\title{
The Renal Effects of an Emergency Department Chloride-restrictive Intravenous Fluid Strategy in Patients Admitted to the Hospital for more than 48 Hours
}

Nor'azim Mohd Yunos, MD ${ }^{1,3}$, Rinaldo Bellomo, MD, FCICM ${ }^{1,2,6}$, David McD

Taylor, FACEM, ${ }^{4,6}$ Simon Judkins, FACEM ${ }^{4}$, Fergus Kerr, FACEM ${ }^{4}$, Harvey

Sutcliffe, Bsc ${ }^{5}$, Colin Hegarty, BSc ${ }^{5}$, Michael Bailey, PhD ${ }^{2}$

1. Department of Intensive Care, Austin Hospital, Melbourne, Australia.

2. Department of Epidemiology and Preventive Medicine, Monash University, Melbourne, Australia.

3. Jeffrey Cheah School of Medicine and Health Sciences, Monash University Malaysia, Malaysia

4. Emergency Department, Austin Hospital, Melbourne, Australia.

5. Department of Pathology, Austin Hospital, Heidelberg, Melbourne, Victoria, Australia

6. School of Medicine, The University of Melbourne, Melbourne, Australia

Address correspondence to:

Dr Nor'azim Mohd Yunos

Jeffrey Cheah School of Medicine and Health Sciences,

This is the author manuscript accepted for publication and has undergone full peer review but has not been through the copyediting, typesetting, pagination and proofreading process, which may lead to differences between this version and the Version of Record. Please cite this article as doi: 10.1111/1742-6723.12821 
Monash University Malaysia,

80100 Johor Bahru, Malaysia

Tel: 60-7-2190 640; Fax: 60-7-2243 311;

Email: nor.azim@monash.edu

NMY co-designed the study, collected the data, analysed and interpreted the data, assisted with statistical analysis and wrote the manuscript. RB co-designed the study, analysed and interpreted the data, assisted with statistical analysis, and edited the manuscript for content. DMT co-designed the study, provided administrative and technical support, and edited the manuscript for content. SJ codesigned the study and provided administrative and technical support. FK codesigned the study and provided administrative and technical support, HS collected the data. $\mathrm{CH}$ collected the data. MB performed the statistical analysis and edited the manuscript for content.

This article is protected by copyright. All rights reserved. 


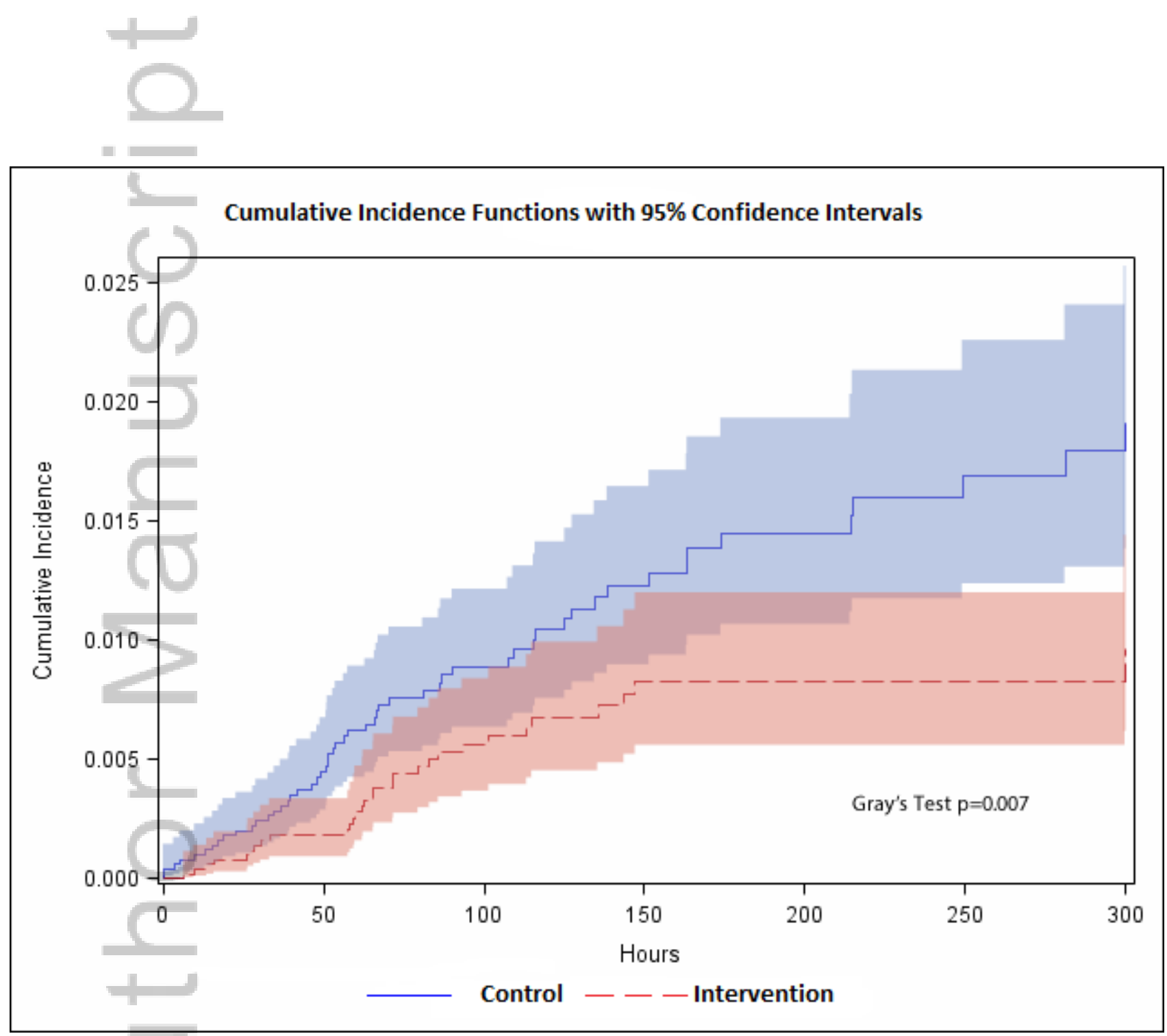

Figure 1 Cumulative Incidence of KDIGO defined Stage 3.tif

This article is protected by copyright. All rights reserved. 


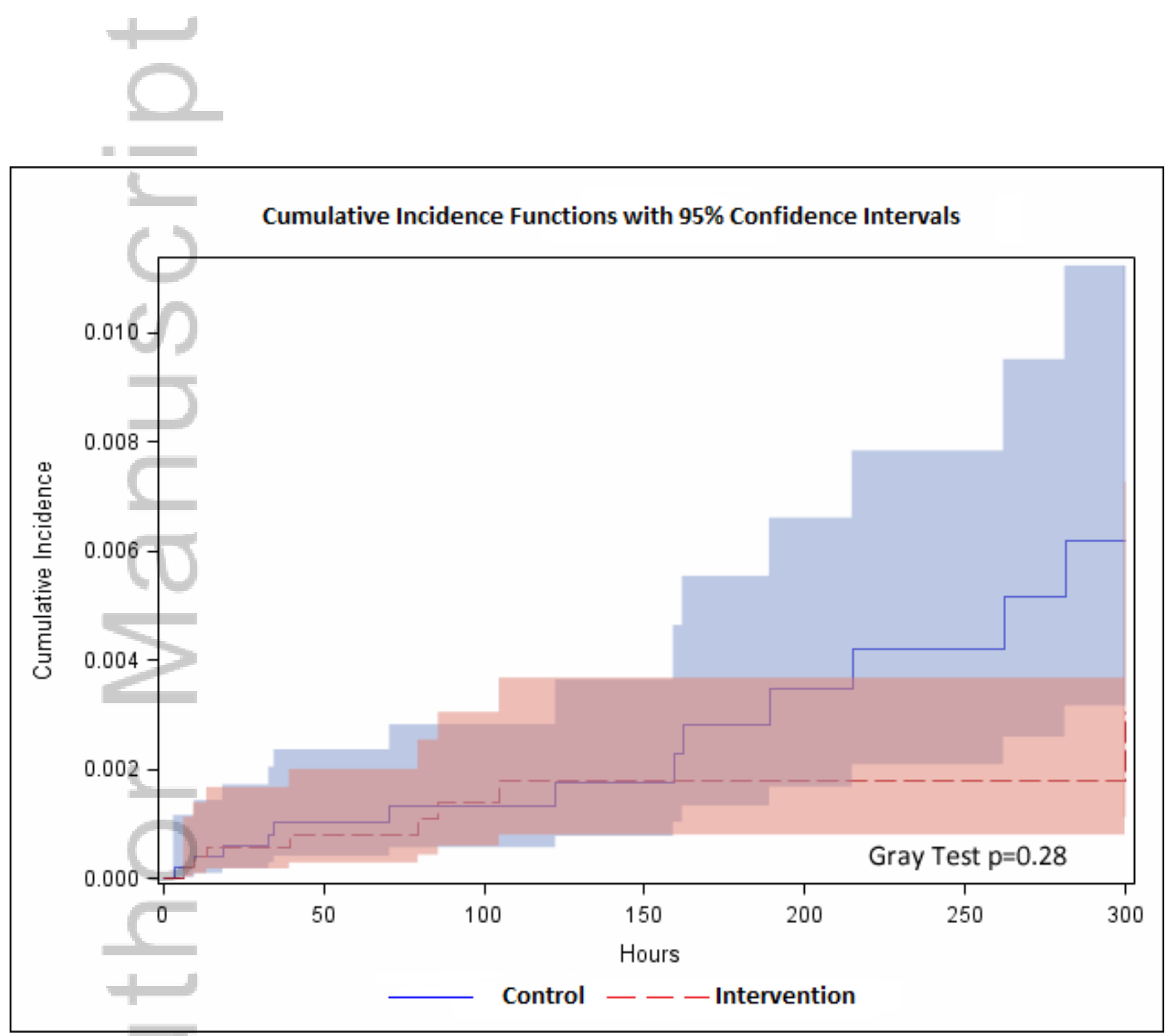

Figure 2 Cumulative Incidence of RRT.tif

This article is protected by copyright. All rights reserved. 


\section{Abstract \\ Objective}

Patients commonly receive intravenous fluids in the Emergency Department (ED). It is still unclear whether the choice of intravenous fluids in this setting influences renal or patient outcomes. We aimed to assess the effects of restricting intravenous chloride administration in the ED on the incidence of acute kidney injury (AKI).

\section{Methods}

We conducted a before-and-after trial with 5008 consecutive ED-treated hospital admissions in the control period and 5146 consecutive admissions in the intervention period. During the control period (18 February 2008 through 17 August 2008), patients received standard intravenous fluids. During the intervention period (18 February 2009 through 17 August 2009), we restricted all chloride-rich fluids. We used the Kidney Disease: Improving Global Outcomes (KDIGO) staging to define AKI.

\section{Results}

Stage 3 of KDIGO-defined AKI decreased from 54 (1.1\%; $95 \% \mathrm{Cl}, 0.8 \%-1.4 \%$ ) to 30 $(0.6 \% ; 95 \% \mathrm{Cl}, 0.4 \%-0.8 \%)(P=.006)$. The rate of Renal Replacement Therapy (RRT) did not change, from $13(0.3 \% ; 95 \% \mathrm{Cl}, 0.2 \%-0.4 \%)$ to $8(0.2 \% ; 95 \% \mathrm{Cl}$, $0.1 \%-0.3 \%)(P=.25)$. After adjustment for relevant covariates, liberal chloride therapy remained associated with a greater risk of KDIGO Stage 3 (hazard ratio 1.82 [95\% Cl 1.13-2.95]; $P=0.01)$. On sensitivity assessment after removing repeat admissions, KDIGO stage 3 remained significantly lower in the intervention period compared with the control period $(P=0.01)$. 


\section{Conclusions}

In a before-and-after trial, a chloride restrictive strategy in an ED was associated with a significant decrease in the incidence of Stage 3 of KDIGO-defined AKI

Keywords: chloride, saline, acute kidney injury, Emergency Departments

\section{Introduction}

Intravenous fluids are commonly prescribed for the treatment of hospital patients, including Emergency Department (ED) patients. However, which intravenous crystalloid fluids should be used for such therapy remains controversial and is the subject of ongoing research. ${ }^{1-4}$

Most of the studies in this area have focused on surgical and critically ill patients. ${ }^{5-7}$ Such studies have suggested that using balanced solutions and avoiding chloriderich solutions may protect the kidneys from additional injury ${ }^{5}$ or may reduce inhospital mortality. ${ }^{6,7}$ In this regard, a before-and-after study of restrictive vs. liberal intravenous chloride fluid administration in a tertiary intensive care unit (ICU), ${ }^{8,9}$ showed an increased incidence of acute kidney injury (AKI) in the liberal intravenous chloride group. In contrast, a recent four-centre cluster randomized controlled trial showed no difference in AKI outcomes between chloride-liberal $0.9 \%$ saline and chloride-restrictive Plasma-Lyte 148 groups of critically ill patients. ${ }^{10}$

The above studies, however, were either affected by marked confounding changes in the use of artificial colloids ${ }^{8,9}$ or by the limited statistical power associated with a cluster trial design. ${ }^{10}$ More relevant to this investigation, neither study addressed the 
impact of chloride restriction during fluid therapy for ED patients, another important cohort of patients who are exposed to significant fluid administration.

We hypothesized that a chloride-restrictive intravenous fluid strategy implemented in the ED might also be associated with decreased severity of AKI during hospital admission and conducted a before-and-after study to test this hypothesis.

\section{Methods}

\section{Study design and setting}

We conducted a prospective, open-label, before-and-after study in the Emergency Department (ED) of the Austin Hospital, a tertiary care hospital affiliated with the University of Melbourne. The local Human Research Ethics Committee approved the study and waived the need for informed consent (Reference: H2008/03445).

\section{Study Population}

We included all consecutive adult admissions to the hospital through the ED during a 6-month control period (18 February 2008 through 17 August 2008) and a 6-month intervention period (18 February 2009 through 17 August 2009). Using the Austin Hospital Inpatient Separation Episodes Database, we excluded patients who had hospital admissions of less than 48 hours, patients with either pre-existing end-stage kidney disease receiving chronic dialysis or patients with pre-existing AKI at ED presentation (defined as KDIGO 2 or 3 upon first serum creatinine reading in ED).

We also excluded patients who were lost to follow up i.e. patients with missing creatinine values. There were 468 such patients $(7.7 \%$ of the original number) in the control group and $485(7.8 \%)$ in the intervention group. 


\section{Study Protocol}

During the 6-month control period, the choice of intravenous fluids for all patients seen in the ED was based on clinician preferences. None of the clinicians was aware of the plan to subsequently restrict intravenous fluids to low chloride solutions. The types of fluids available included $0.9 \%$ saline (chloride concentration: $150 \mathrm{mmol} / \mathrm{L}$ ) (Baxter Pty Ltd), lactated crystalloid solution (chloride concentration $109 \mathrm{mmol} / \mathrm{L}$ ) (Hartmann solution, Baxter Pty Ltd), balanced buffered solution (chloride concentration: 98 mmol/L) (Plasma-Lyte 148, Baxter Pty Lts) and succinylated gelatin solution (chloride concentration $120 \mathrm{mmol} / \mathrm{L}$ ) (Gelofusine, BBraun).

We used the next 6 months as a "washout period". During this period, we announced the decision to remove chloride-rich fluids from ED practice and educated all ED staff on the shift in intravenous fluid practice to a chloride-restrictive approach.

During the 6-month intervention period, we then restricted the intravenous fluids used in the ED to low chloride solutions only. All patients seen in ED received either lactated crystalloid solution (chloride concentration: $109 \mathrm{mmol} / \mathrm{L}$ ) (Hartmann solution, Baxter Pty Ltd) or balanced buffered solution (chloride concentration: $98 \mathrm{mmol} / \mathrm{L}$ ) (Plasma-Lyte 148, Baxter Pty Lts).

During this period, chloride-rich fluids were now available only for specific conditions like severe hyponatremia and traumatic brain injury and under prescription by an ED specialist.

The choice of intravenous fluids on the general hospital wards, following admission through the ED, was not modified and was left to clinician preferences. 


\section{Measurements and Outcomes}

We collected key demographic data including age, sex and admitting diagnosis of all the enrolled admissions. We retrieved pre-hospital admission serum creatinine concentrations and daily morning creatinine concentrations during hospital admission from the computerized central laboratory database.

The primary outcome was the incidence of AKI according to the Kidney Disease: Improving Global Outcomes (KDIGO) creatinine definitions during the hospital admission. ${ }^{11}$ Secondary outcomes included the need for Renal Replacement Therapy (RRT), length of stay in hospital and hospital survival. We defined baseline creatinine concentration as the lowest creatinine concentration available prior to hospital admission; when a measurement was not available, we estimated creatinine concentration using the Modification of Diet in Renal Disease (MDRD) equation (assuming a lower limit of normal baseline GFR of $75 \mathrm{~mL} / \mathrm{min}) .^{12}$

\section{Data Analyses}

As sample size was determined by the number of patients admitted during two six month periods, the following power calculations have been performed retrospectively. With $>4300$ patients admitted to ED per 6 months, this study had an $87 \%$ power (twosided $\mathrm{P}$ value of 0.01 ) to detect a difference in the absolute proportion of patients with $\mathrm{AKI}$ of $1 \%$ ( $1 \%$ vs $2 \%$ ) and a $90 \%$ power to detect an absolute difference in the proportion of patients requiring RRT of $0.7 \%(0.3 \%$ vs $1.0 \%)$. Differences of these magnitudes were judged to be both possible and of clinical importance.

All statistical analyses were performed using Stata version 11 (StataCorp) and SAS version 9.4 (SAS Institute Inc., Cary, NC, USA). We performed baseline comparisons using Chi-square tests for equal proportion with results reported as 
numbers, percentages, and $95 \%$ confidence intervals. Continuous normally distributed variables were compared using Student t-tests and presented as means $(95 \% \mathrm{Cl})$ while non-normally distributed data was compared using Wilcoxon rank sum tests and presented as medians (interquartile range, IQR). Outcomes were compared using Cox-Proportional Hazards regression for time to event analysis, logistic regression for binomial outcomes and linear regression for log-transformed lengths of stay, with results presented as Hazard Ratios $(95 \% \mathrm{Cl})$, Odds Ratios $(95 \% \mathrm{Cl})$ and geometric means $(95 \% \mathrm{Cl})$ respectively. To account for competing risk, survival times are presented as cumulative incidence graphs with a corresponding comparison of groups performed using Gray's test. ${ }^{13}$ Multivariable models were constructed adjusting for the pre-defined covariates; gender, age, diagnosis, surgical status, admission number per patient and baseline creatinine. To further account for repeat admissions, additional sensitivity analysis was conducted considering each patient's first admission only. Proportional hazard assumptions were assessed using log-log plots while goodness of fit and model discrimination for logistic regression models were reported using Hosmer-Lemeshow and AUROC $(95 \% \mathrm{Cl})$ respectively. To increase the robustness of our findings, a two-sided $p$-value of 0.01 was used to indicate statistical significance.

\section{Results}

\section{Characteristics of study subjects}

We studied 8638 patients experiencing 10154 ED admissions: 4299 patients experiencing 5008 admissions during the control period and 4339 patients experiencing 5146 admissions during the intervention period. The baseline 
characteristics of the patients during the control and the intervention periods are shown in Table 1. The two groups were similar with regard to age, sex, admission diagnosis, and baseline creatinine concentration. During the control period, 3216 admissions $(64.2 \%$; 95\% Cl 62.9\% - 65.5\%) did not have a baseline creatinine level available and had the level estimated with the MDRD equation compared with 3294 admissions $(64 \% ; 95 \% \mathrm{Cl} 62.7 \%-65.3 \%)$ during the intervention period $(P=.83)$.

Table 2 shows the composition of the study fluids. The intervention resulted in significant changes in intravenous fluid therapy in the ED. Overall, $0.9 \%$ saline prescription decreased from $7200 \mathrm{~L}$ to $79 \mathrm{~L}$ (99\% reduction; 1.4 vs 0.02 L/admission; $P<0.001)$ and $4 \%$ gelatin solution from $112 \mathrm{~L}$ to $1.5 \mathrm{~L}(99 \%$ reduction, 0.02 vs 0.003 L/admission; $P<0.001)$. Conversely, Hartmann solution prescription increased from $870 \mathrm{~L}$ to $8217 \mathrm{~L}(89 \%$ increase, 0.2 vs $1.6 \mathrm{~L}$ /admission; $P<0.001)$, and PlasmaLyte ${ }^{\circledR}$ prescription from $49 \mathrm{~L}$ to $230 \mathrm{~L}(79 \%$ increase, 0.001 vs. $0.04 \mathrm{~L} /$ admission; $P$ $<0.01$ ), with an overall saving of AUD\$2,143.4.

The above changes in fluid therapy translated into a decrease in fluid-related chloride administration by a total of $262,984 \mathrm{mmol}$, or from 238 to $181 \mathrm{mmol} / \mathrm{admission}$ over the 6-month period. Similarly, sodium administration decreased from 243 to 215 mmol/ admission. In contrast, study fluid-related potassium administration increased from 2.4 to $9 \mathrm{mmol} /$ patient and lactate administration from 5 to $46 \mathrm{mmol} /$ patient.

\section{Primary Outcomes}

Table 3 shows the KDIGO definition and the staging of $\mathrm{AKI} .{ }^{11}$ The patients who were admitted to the ward for more than 48 hours after receiving a chloride-restrictive fluid strategy in the ED had a statistically significant lower incidence of Stage 3 KDIGO- 
defined AKI and a non-significant decrease in RRT use (Table 4). Cumulative incidence plots of both outcomes are presented in Figures 1 and 2.

Compared with the intervention period, the risk of Stage 3 of KDIGO-defined AKI remained significantly greater during the chloride-rich control phase for both crude [hazard ratio $1.83(95 \% \mathrm{Cl} 1.16-2.89) ; P=0.01$ ] and adjusted [hazard ratio $1.74(95 \%$ $\mathrm{Cl} 1.10-2.76) ; P=0.01$ ] levels. These findings were confirmed when analysed using logistic regression with crude odds ratio $1.86(95 \% \mathrm{Cl} 1.19-2.91)(P=0.01)$ and adjusted odds ratio $1.81(95 \% \mathrm{Cl} 1.14-2.85)(P=0.01)$. These findings remained significant when considering only first admissions to ED (supplementary appendix ETables 1 and 2). Supplementary appendix E-Table 3 shows the simplified baseline characteristics of the Stage 3 of KDIGO-defined AKI subgroup of patients, and the time to the Stage 3 KDIGO-defined AKI event.

\section{Secondary Outcomes}

210 patients died in-hospital $(4.9 \% ; 95 \% \mathrm{Cl} 4.3 \%-5.5 \%)$ during the control period compared with 192 patients (4.4\%; 95\% Cl 3.8\%-5.2\%) during the intervention period $(P=0.31)$. Median hospital length of stay was 4 days (IQR, 2-9 days) vs. 4 days (IQR 2-8 days), respectively $(P=0.14)$. Supplementary appendix $E-T a b l e ~ 4$ shows the secondary outcomes of the Stage 3 of KDIGO-defined AKI subgroup of patients

\section{Discussion}

\section{Key findings}

In a before-and-after study involving more than 8,000 patients admitted to hospital via the Emergency Department of a tertiary hospital, we found that a chloride 
restrictive fluid management approach was associated with a significant decrease in KDIGO stage 3 acute kidney injury.

\section{Comparison with Previous Studies}

To our knowledge, no interventional studies have assessed the renal effects of a chloride-restrictive intravenous fluid strategy for ED patients. The closest relevant study is a recent large retrospective cohort investigation that studied the initial fluid choice in the first two hospital days among more than 60,000 patients diagnosed with sepsis. ${ }^{14}$ This study, however, focused on in-hospital mortality instead of renal outcomes and found a significant association between a chloride-liberal initial fluid choice and higher mortality.

The reduced incidence of Stage $3 \mathrm{KDIGO}$ seen in our study is consistent with controlled double-blinded human studies that reported better renal cortical tissue perfusion with lower chloride fluids compared with saline. ${ }^{15,16}$ It is also consistent with several previous observational clinical studies linking excessive chloride administration and chloride levels with increased risk of renal dysfunction or mortality. $^{5-9}$

\section{Significance of Study Findings}

Our before-and-after study provides evidence to suggest that the initial fluid choice in the treatment of ED patients may have an impact on subsequent renal outcomes during their hospital stay. As such, it implies that ED implementation of a chloriderestrictive strategy may reduce the incidence of severe AKI (KDIGO stage 3). This observation adds to existing concerns with the use of $0.9 \%$ saline ${ }^{17-20}$ and to the long list of studies that have highlighted worse outcomes ${ }^{5-8,9,21}$ with $0.9 \%$ saline instead of balanced crystalloids. Our findings indirectly support the avoidance of chloride-rich 
gelatin solutions, also separately linked with unfavourable renal outcomes, ${ }^{22}$ and, given the equivalent cost of lactated solutions, imply that there is no cost benefit of giving saline to ED patients. Thus, from a renal point view and a health care cost point of view, our study implies that there is no logical reason to administer saline to ED patients outside of specific indications.

\section{Strengths of study}

To our knowledge, this is the first study to compare the changes in renal outcomes associated with an IV fluid therapy strategy based on a chloride-restrictive approach vs. a chloride-liberal approach in the ED setting. Moreover, the study population was large and the outcome difference remained significant after correction for baseline characteristics. Finally, the changes in intravenous fluid practice and the separation in the amount of chloride given were clear with decreased chloride administration by more than a quarter million millimoles and a decrease in saline administration of $99 \%$.

\section{Limitations}

Our study had a number of important limitations. Our intervention was not a randomized controlled trial and was not blinded. However, there were no significant practice changes implanted in the ED of our institution during this before-and-after study and the baseline characteristics of our patients did not differ between the two groups. Furthermore, lack of blinding would not have biased the measurement of serum creatinine during the subsequent hospital stay.

A further limitation of our study was its single-centre design, which might have reduced its external validity. However, our ED has all the typical features of a tertiary hospital ED in the developed world, making our findings likely relevant to similar 
institutions. Our study also did not include the larger group of ED patients - those discharged on the same day or short hospital stay of less than 48 hours - limiting its generalizability to all patients seen in ED.

We did not collect information on individual intravenous fluid administration and cannot exclude the potential confounding effects of succinylated gelatin solution on renal outcomes. ${ }^{22-26}$ However, the change in gelatin use in our study represented only a total of $110.5 \mathrm{~L}$ (average decrease of approximately $22 \mathrm{ml} /$ patient) and was much less than the $>7100 \mathrm{~L}$ decrease in saline administration (average decrease of approximately $1.4 \mathrm{~L} /$ patient).

We did not collect information on IV fluids use after the transfer from ED to the ward. However, the present study aimed to test the hypothesis that even an early ED application of chloride-restrictive policy could result in changes in renal outcomes during hospital stay. Moreover, no general wards were notified of the study or requested to continue ED fluids as prescribed. We hope future studies will extend the analysis into the potential larger volume of fluids received during the hospital admissions.

The assessment of baseline creatinine is a recognized issue in the analysis of AKI. ${ }^{27}$ In patients for whom such information was absent, we estimated the premorbid creatinine concentrations using the MDRD equation. This method has limitations. However, inaccuracies arising from its use are unlikely to have biased our results as they applied to both periods. In addition, the outcomes were objective and dependent on laboratory tests, which were not amenable to ascertainment bias or manipulation. 


\section{Conclusions}

We conducted a before-and-after study comparing the renal effects of a chloriderestrictive versus a chloride liberal intravenous fluid strategy in the ED setting. We found that, in ED patients admitted to the hospital for more than 48 hours, a chloriderestrictive fluid strategy in ED was associated with a statistically significant decrease in the incidence of Stage 3 KDIGO-defined AKI. However, we did not find any significant effect on need for RRT or mortality. Our observations from this large study of thousands of ED patients to support ongoing concern about the renal safety of excessive intravenous chloride-rich fluid administration.

\section{Acknowledgements}

We acknowledge the Pathology Department for their kind assistance in obtaining the creatinine results required for this study and the Pharmacy Department for study fluid delivery, monitoring and reconciliation.

\section{Competing Interests Declaration}

Rinaldo Bellomo has received consultancy fees from Baxter and BBraun and grant money from Baxter. Both Baxter and BBraun have also paid for Rinaldo Bellomo's travel and accommodation, and meeting expenses 


\section{References}

1. Young P. Saline is the solution for crystalloid resuscitation. Crit Care Med. 2016; 44(8): 1538-1540

2. Semler MW, Rice TW. Saline is not the first choice for crystalloid resuscitation fluids. Crit Care Med. 2016; 44(8): 1541-1544

3. Reddy SK, Young PJ, Beasley RW, et al. Overview of the study protocols and statistical analysis plan for the Saline versus Plasma-Lyte 148 for Intravenous Fluid Therapy (SPLIT) research program. Crit Care Resusc. 2015; 17: 29-36

4. Glassford NJ, French CJ, Bailey M, et al. Changes in intravenous fluid use patterns in Australia and New Zealand: evidence of research translating into practice. Crit Care Resusc 2016; 18: 78-88.

5. Shaw AD, Bagshaw SM, Goldstein SL, et al. Major complications, mortality, and resource utilization after open abdominal surgery: $0.9 \%$ saline compared to Plasma-Lyte. Ann Surg 2012; 255: 821-829.

6. Raghunathan K, Shaw A, Nathanson B, et al. Association between the choice of IV crystalloid and in-hospital mortality among critically ill adults with sepsis.

Crit Care Med. 42: 2014; 1585-1591

7. Shaw AD, Raghunathan K, Peyerl FW, et al. Association between intravenous chloride load during resuscitation and in-hospital mortality among patients with SIRS. Intensive Care Med. 2014; 40: 1897-1905 
8. Yunos NM, Bellomo R, Hegarty C, et al. Association between a chloride-liberal vs chloride-restrictive intravenous fluid administration strategy and kidney injury in critically ill adults. JAMA. 2012; 308: 1566-1572

9. Yunos NM, Bellomo R, Glassford N, et al. Chloride-liberal vs. chloriderestrictive intravenous fluid administration and acute kidney injury: an extended analysis. Intensive Care Med. 2015; 41: 257-264

10. Young P, Bailey M, Beasley R, et al. Effect of a buffered crystalloid solution vs. saline on acute kidney injury among patients in the Intensive Care Unit: The SPLIT randomized clinical trial. JAMA. 2015; 314(16): 1701-1710

11. Kidney Disease: Improving Global Outcomes (KDIGO) acute kidney injury work group. KDIGO clinical practice guideline for acute kidney injury. Kidney Int. 2012; Suppl 2: 19-36.

12. Závada J, Hoste E, Cartin-Ceba R, et al. A comparison of three methods to estimate baseline creatinine for RIFLE classification. Nephrol Dial Transplant. 2010; 25: 3911-3918.

13. Gray R. A class of K-sample tests for comparing the cumulative incidence of a competing risk. Ann Stat. 1988; 16: 1141-1154

14. Raghunathan K, Bonavia A, Nathanson BH, et al. Association between initial fluid choice and subsequent in-hospital mortality during the resuscitation of adults with septic shock. Anesthesiology. 2015; 123(6): 1385-93

15. Chowdhury AH, Cox EF, Francis ST, et al. A randomized, controlled, doubleblind crossover study on the effects of $2-L$ infusions of $0.9 \%$ saline and 
Plasma-Lyte 148 on renal blood flow velocity and renal cortical tissue perfusion in healthy volunteers. Ann Surg. 2012; 256: 18-24.

16. Chowdhury AH, Cox EF, Francis ST, et al. A randomized, controlled, doubleblind crossover study on the effects of $1-L$ infusions of $6 \%$ hydroxyethyl starch suspended in $0.9 \%$ saline (Voluven) and a balanced solution (Plasma Volume Redibag) on blood volume, renal blood flow velocity, and renal cortical tissue perfusion in healthy volunteers. Ann Surg. 2014; 259: 881-887

17. Wakim KG. "Normal" 0.9 percent salt solution is neither "normal' nor physiological. JAMA. 1970; 214(9): 1710

18. Yunos NM, Kim IB, Bellomo R, eta al. The biochemical effects of restricting chloride-rich fluids in intensive care. Crit Care Med. 2011; 39: 2419-2424.

19. Scheingraber S, Rehm M, Sehmisch C, et al. Rapid saline infusion produces hyperchloremic acidosis in patients undergoing gynecologic surgery. Anesthesiology. 1999; 90(5): 1265-70.

20. Verma B, Luethi N, Cioccari L, et al. A multicentre randomised controlled pilot study of fluid resuscitation with saline or Plasma-Lyte 148 in critically ill patients. Crit Care Resusc. 2016; 18(3): 205-12.

21. Rochwerg B, Alhazzani W, Sindi A, et al. Fluid resuscitation in sepsis: a systematic review and network meta-analysis. Ann Intern Med. 2014; 161(5): 347-55

22. Pisano A Landoni G, Bellomo R. The risk of infusing gelatin? Die-hard misconceptions and forgotten (or ignored) truths. Minerva Anestesiol 2016; 82: $1107-1114$ 
23. Schick MA, Isbary TJ, Schlegel N, et I. The impact of crystalloid and colloid infusion on the kidney in rodent sepsis. Intensive Care Med. 2010; 36: 541548

24. Simon TP, Schuerholz T, Hüter L, et al. Impairment of renal function using hyperoncotic colloids in a two hit model of shock: a prospective randomized study. Crit Care. 2012; 16(1): R16

25. Bayer O, Schwarzkopf D, Doenst T, et al. Perioperative fluid therapy with tetrastarch and gelatin in cardiac surgery-a prospective sequential analysis. Crit Care Med. 2013; 41(11): 2532-2542

26. Bayer O, Reinhart K, Kohl M, et al. Effects of fluid resuscitation with synthetic colloids or crystalloids alone on shock reversal, fluid balance and patient outcomes in patients with severe sepsis: a prospective sequential analysis.

Crit Care Med. 2012; 40(9): 2543-2551

27. Cruz DN, Ricci Z, Ronco C. Clinical review: RIFLE and AKIN - time for reappraisal. Critical Care. 2009; 13: 211 
Table 1. Baseline characteristics of the patient admissions during the control and intervention periods

\begin{tabular}{|c|c|c|}
\hline & \multicolumn{2}{|c|}{ No. (\%) $[95 \% \mathrm{Cl}]$ of Admissions ${ }^{\mathrm{a}}$} \\
\hline+ & $\begin{array}{l}\text { Control Period } \\
\qquad(n=5008)\end{array}$ & $\begin{array}{l}\text { Intervention Period } \\
\qquad(n=5146)\end{array}$ \\
\hline Male & $2692(54)[52-55]$ & 2754 (54) [52-55] \\
\hline Surgical status $^{b}$ & $1187(23)[22-24]$ & $1167(24)[23-25]$ \\
\hline Repeat admission & 709 (14) [13-15] & $807(16)[15-17]$ \\
\hline \multicolumn{3}{|l|}{ Diagnostic Group } \\
\hline Cardiology & $412(8.2)[7.5-9.0]$ & $360(7)$ [6-8] \\
\hline Colorectal & $161(3.2)[2.8-3.7]$ & $174(3.4)[2.9-3.9]$ \\
\hline Emergency & $530(10.6)[9.8-11.5]$ & $546(10.6)[9.8-11.5]$ \\
\hline Endocrinology & $50(1)[0.8-1.3]$ & $51(1)[0.8-1.3]$ \\
\hline General Medicine & $1244(25)[24-26]$ & $1198(23)[22-24]$ \\
\hline Haematology & $71(1.4)[1.1-1.8]$ & $90(1.7)[1.4-2.1]$ \\
\hline Hepatobiliary & $281(5.6)[5.0-6.3]$ & $305(5.9)[5.3-6.6]$ \\
\hline Infectious disease & $54(1.1)[0.8-1.4]$ & 78 (1.5) [1.2-1.9] \\
\hline Liver & $90(1.8)[1.5-2.2]$ & $73(1.4)[1.1-1.8]$ \\
\hline Neurology & $134(2.7)[2.3-3.2]$ & $136(2.6)[2.2-3.1]$ \\
\hline Neurosurgery & $56(1.1)[0.9-1.5]$ & 66 (1.3) [1.0-1.6] \\
\hline Oncology & 249 (5) [4.4-5.6] & 259 (5) [4.5-5.7] \\
\hline Orthopaedics & $267(5.3)[4.7-6.0]$ & $297(5.8)[5.2-6.4]$ \\
\hline Plastic surgery & $128(2.6)[2.2-3.0]$ & $83(1.6)[1.3-2.0]$ \\
\hline Respiratory & $221(4.4)[3.9-5.0]$ & $265(5.1)[4.6-5.8]$ \\
\hline Spinal & $61(1.2)[0.9-1.6]$ & $63(1.2)[1.0-1.6]$ \\
\hline Stroke & $239(4.8)[4.2-5.4]$ & $276(5.4)[4.8-6.0]$ \\
\hline
\end{tabular}




\begin{tabular}{|l|c|c|}
\hline Upper gastrointestinal & $246(4.9)[4.4-5.6]$ & $289(5.6)[5.0-6.3]$ \\
\hline Urology & $91(1.8)[1.5-2.2]$ & $83(1.6)[1.3-2.0]$ \\
\hline & \multicolumn{2}{|c|}{ Mean $(95 \% \mathrm{Cl})$} \\
\hline Age in years & $63.9(63.3-64.5)$ & $63.2(62.6-63.8)$ \\
\hline Baseline creatinine in & $86.5(85.8-87.2)$ & $86.0(85.3-86.7)$ \\
\hline Mmol/L & & \\
\hline
\end{tabular}

SI conversion factor: To convert creatinine to $\mathrm{mg} / \mathrm{dL}$, divide by 88.4 .

${ }^{a}$ The control period was from February 18, 2008 through August 17, 2008, and the intervention period was from February 18, 2009 through August 17, 2009.

${ }^{\mathrm{b}} \mathrm{Had}$ surgery during the admission

This article is protected by copyright. All rights reserved. 
Table 2. Composition and prices of study fluids ${ }^{a, b}$

\begin{tabular}{|c|c|c|c|c|}
\hline & $0.9 \%$ saline & Hartmann & $4 \%$ Gelatin & $\begin{array}{l}\text { Plasma-Lyte } \\
148\end{array}$ \\
\hline Sodium & 150 & 129 & 154 & 140 \\
\hline $\begin{array}{l}\text { Potassium } \\
\end{array}$ & 0 & 5 & 0 & 5 \\
\hline Chloride & 150 & 109 & 120 & 98 \\
\hline Calcium & 0 & 2 & 0 & 0 \\
\hline Magnesium & 0 & 0 & 0 & 1.5 \\
\hline Lactate & 0 & 29 & 0 & 0 \\
\hline Acetate & 0 & 0 & 0 & 27 \\
\hline Gluconate & 0 & 0 & 0 & 23 \\
\hline Octanoate & 0 & 0 & 0 & 0 \\
\hline Price & $\$ 1.09$ per $1 \mathrm{~L}$ & $\$ 1.06$ per $1 \mathrm{~L}$ & $\$ 23$ per $1 \mathrm{~L}$ & \$ 2.15 per $1 \mathrm{~L}$ \\
\hline
\end{tabular}

${ }^{\mathrm{a}}$ All concentrations in $\mathrm{mmol} / \mathrm{L}$

${ }^{\mathrm{b}}$ All prices in AUD

This article is protected by copyright. All rights reserved. 


\section{Table 3 KDIGO definition and staging of $A K I^{11}$}

$\mathrm{AKI}$ is defined as any of the following: increase in serum creatinine by $\geq 26.5 \mu \mathrm{mol} / \mathrm{I}$ within 48 hours; or increase in serum creatinine $\geq 1.5$ times baseline, which is known or presumed to have occurred within the prior 7 days; or urine volume $<0.5 \mathrm{ml} / \mathrm{kg} / \mathrm{h}$ for 6 hours.

\begin{tabular}{|l|l|l|}
\hline Stage & Serum creatinine & Urine output \\
\hline 1 & $1.5-1.9$ times baseline OR $\geq 26.5 \mu \mathrm{mol} / \mathrm{l}$ & $<0.5 \mathrm{ml} / \mathrm{kg} / \mathrm{h}$ for $6-12$ \\
& increase within 48 hours & hours \\
\hline 2 & $2.0-2.9$ times baseline & $<0.5 \mathrm{ml} / \mathrm{kg} / \mathrm{h}$ for $\geq 12$ \\
& & hours \\
& creatinine to $\geq 353.6 \mu$ times baseline OR increase in serum & $<0.3 \mathrm{ml} / \mathrm{kg} / \mathrm{h}$ for $\geq 24$ \\
& renal replacement therapy & hours OR anuria $\geq 12$ \\
& \multicolumn{2}{|c|}{ hours } \\
\hline
\end{tabular}


Table 4 Incidence of Acute Kidney Injury Stratified by Kidney Disease

Improving Global Outcomes (KDIGO) Serum Creatinine Criteria

\begin{tabular}{|c|c|c|r|}
\hline & \multicolumn{2}{|c|}{ No. (\%) [95\% Cl] of events ${ }^{\text {a }}$} & \\
\hline & $\begin{array}{c}\text { Control Period } \\
(\mathbf{n = 5 0 0 8 )}\end{array}$ & $\begin{array}{c}\text { Intervention Period } \\
(\mathbf{n = 5 1 4 6 )}\end{array}$ & $\boldsymbol{P}$ value \\
\hline $\begin{array}{l}\text { KDIGO } \\
\text { Classification } \\
\text { Stage 1 }\end{array}$ & Number (\%) [95\%Cl] & Number (\%) [95\%Cl] & \\
\hline Stage 2 & $626(12.5)[11.6-13.4]$ & $703(13.7)[12.8-14.6]$ & .08 \\
\hline Stage 3 & $97(1.9)[1.6-2.4]$ & $99(1.9)[1.6-2.3]$ & .96 \\
\hline RRT & $54(1.1)[0.8-1.4]$ & $30(0.6)[0.4-0.8]$ & .006 \\
\hline
\end{tabular}

\footnotetext{
a The control period was from February 18, 2008 through August 17, 2008, and the intervention period was from

February 18, 2009 through August 17, 2009.
}

Figure Legends

Figure 1 Cumulative Incidence of KDIGO-defined Stage $3^{\text {a }}$

${ }^{\text {a }}$ Cumulative risk is low, $<0.1 \%$

Figure 2 Cumulative Incidence of RRT

${ }^{a}$ Cumulative risk is low, $<0.1 \%$ 


\section{University Library}

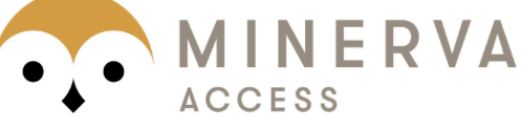

A gateway to Melbourne's research publications

Minerva Access is the Institutional Repository of The University of Melbourne

Author/s:

Yunos, NM;Bellomo, R;Taylor, DM;Judkins, S;Kerr, F;Sutcliffe, H;Hegarty, C;Bailey, M

Title:

Renal effects of an emergency department chloride-restrictive intravenous fluid strategy in patients admitted to hospital for more than 48 hours

Date:

2017-12-01

Citation:

Yunos, N. M., Bellomo, R., Taylor, D. M., Judkins, S., Kerr, F., Sutcliffe, H., Hegarty, C. \& Bailey, M. (2017). Renal effects of an emergency department chloride-restrictive intravenous fluid strategy in patients admitted to hospital for more than 48 hours. EMERGENCY

MEDICINE AUSTRALASIA, 29 (6), pp.643-649. https://doi.org/10.1111/1742-6723.12821.

Persistent Link:

http://hdl.handle.net/11343/293008 